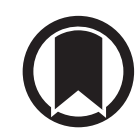

CrossMark

\title{
"Truth is ever to be found in simplicity, and not in the multiplicity and confusion of things" - Sir Isaac Newton
}

\author{
To the Editor:
}

We read with interest the recent publication by Morice et al. [1] "The effect of gefapixant, a P2X3 antagonist, on cough reflex sensitivity: a randomised placebo-controlled study" and the accompanying editorial by TURnER and Birring [2] "Chronic cough: ATP, afferent pathways and hypersensitivity". The authors of both publications conclude the results are suggestive of two separate neuronal pathways mediating the cough reflex; however, there are significant issues with this interpretation of the data.

Gefapixant is a first in class therapy that blocks the effects of ATP (adenosine triphosphate) at P2X3 and also P2X2/3 ion channels on sensory nerves, and has already been shown to be highly efficacious at reducing the frequency of coughing in patients with refractory chronic cough [3, 4]. MoricE et al. [1] studied the effects of a single dose of gefapixant on experimentally evoked cough in healthy volunteers and patients with refractory chronic cough. Participants underwent four different cough challenges (capsaicin, citric acid, distilled water and ATP) after taking gefapixant and a matched placebo, in a double blinded randomised trial.

This study found gefapixant reduces cough evoked by ATP and distilled water, but not citric acid or capsaicin; distilled water is a hypotonic challenge, which we have shown to be capable of activating airway nerves through release of ATP [5]. The data are therefore consistent with gefapixant blocking P2X3 channels and preventing airway nerve activation by ATP but having no effect on nerve activation by capsaicin or citric acid, which are known to evoke cough via a range of other ion channels; capsaicin activates nerves via transient receptor vanilloid 1 (TRPV1), whereas citric acid is thought to activate TRPV1, transient receptor potential ankyrin 1 (TRPA1) and acid-sensing ion channels (ASIC) $[6,7]$. However, in both the manuscript and the accompanying editorial, the authors misinterpret this data, suggesting these findings indicate two separate peripheral neuronal pathways mediating cough. This is highly unlikely given P2X3 and TRPV1 channels are well known to be expressed by the same airway nerves $[8,9]$. Furthermore, the findings are readily explained by the activation of a single nerve pathway expressing both P2X3 and TRPV1 ion channels, with only P2X3 being blocked by gefapixant.

In addition to issues with the data interpretation, there are concerns about the study design. As MoRICE et al. [10] have previously shown, capsaicin and citric acid cough challenges interact with one another, inducing reduced cough responses to one another, probably via tachyphylaxis; these effects persist for at least $6 \mathrm{~h}$; whether similar effects occur with distilled water and ATP is unknown. Therefore, a study designed to include 12 cough challenges on the same day will inevitably be plagued by interactions between all the challenges. This could have been mitigated by randomisation of the order of the challenges to include all the possible combinations and enrolling sufficient patients to represent all possible sequences; unfortunately, this was not done. The authors and commentary writers argue this was not a problem as each subject acted as their own control; however, as not all challenge sequences were represented, a systematic effect of the challenge order influencing the results cannot be ruled out, nor adequately evaluated statistically. We would therefore suggest that this methodological problem in the design should have restricted the interpretation of the data to cautious conclusions, instead of declaring evidence for new peripheral pathways mediating cough.

The peripheral and central mechanisms involved in refractory chronic cough are complex and currently poorly understood. Evidence from pre-clinical models shows that several neuronal pathways are capable of

@ERSpublications

Over interpretation of cough challenge data only adds to the confusion in our understanding of the mechanisms underlying chronic cough http://bit.ly/2X52CQt

Cite this article as: Smith JA, Wortley MA, Bonvini S, et al. "Truth is ever to be found in simplicity, and not in the multiplicity and confusion of things" - Sir Isaac Newton. Eur Respir J 2020; 55: 1901566 [https://doi.org/10.1183/13993003.01566-2019]. 
activating the cough reflex; for example, both chemically sensitive C-fibres and mechanically sensitive A $\delta$ fibres play a role. However, they do not support the paradigm of discrete endogenous and exogenous pathways proposed by TURNER and BIRRING [2]. We suggest that the most appropriate interpretation of the data presented by MoRice et al. [1] is that, notwithstanding significant shortcomings in the study design, they simply provide clinical evidence that gefapixant blocks the P2X3 but not the TRPV1 receptor in the lung, i.e. confirm its known mechanism of action. We would caution that such over-extrapolation of clinical cough challenge data only adds to confusion in the field.

Jaclyn A. Smith ${ }^{1,2}$, Mike A. Wortley ${ }^{3}$, Sara Bonvini ${ }^{3}$, Mark Birrell ${ }^{3,4}$ and Maria G. Belvisi ${ }^{3,4}$

${ }^{1}$ Division of Infection, Immunity and Respiratory Medicine, University of Manchester, Manchester, UK. ${ }^{2}$ Manchester University NHS Foundation Trust, Manchester, UK. ${ }^{3}$ Respiratory Pharmacology Group, Airway Disease, National Heart and Lung Institute, Imperial College London, London, UK. ${ }^{4}$ Respiratory, Inflammation and Autoimmune (RIA), BioPharmaceuticals R\&D, AstraZeneca, Sweden.

Correspondence: Jaclyn A. Smith, Division of Infection, Immunity and Respiratory Medicine, University of Manchester, Education and Research Centre, Manchester University NHS Foundation Trust, Wythenshawe Hospital, Southmoor Rd, Manchester M23 9LT, UK. E-mail: jacky.smith@manchester.ac.uk

Received: 6 Aug 2019 | Accepted after revision: 1 Nov 2019

Conflict of interest: J.A. Smith reports grants for commercial research and personal fees for advisory board work and consultancy from GlaxoSmithKline and Merck, grants for commercial research and personal fees for consultancy from NeRRe Pharmaceuticals, Menlo, Bayer and Axalbion, personal fees for consultancy from Boehringer Ingelheim, Genentech, Neomed, Chiesi and Bellus, non-financial support (equipment provision) from Vitalograph, grants from Afferent, research grants and personal fees for consultancy from AstraZeneca, outside the submitted work; and has a patent regarding a method for generating output data licensed. M.A. Wortley has nothing to disclose. S. Bonvini has nothing to disclose. M. Birrell is an employee of AstraZeneca. M.G. Belvisi is an employee of AstraZeneca.

\section{References}

1 Morice AH, Kitt MM, Ford AP, et al. The effect of gefapixant, a P2X3 antagonist, on cough reflex sensitivity: a randomised placebo-controlled study. Eur Respir J 2019; 54: 1900439.

2 Turner RD, Birring SS. Chronic cough: ATP, afferent pathways and hypersensitivity. Eur Respir J 2019; 54: 1900889.

3 Abdulqawi R, Dockry R, Holt K, et al. P2X3 receptor antagonist (AF-219) in refractory chronic cough: a randomised, double-blind, placebo-controlled phase 2 study. Lancet 2015; 385: 1198-1205.

4 Smith JA, Kitt MM, Morice AH, et al. MK-7264, a P2X3 receptor antagonist, reduces cough frequency in patients with refractory chronic cough: results from a randomized, controlled, phase $2 \mathrm{~b}$ clinical trial. Am J Respir Crit Care Med 2017; 195: A7608.

5 Bonvini SJ, Birrell MA, Grace MS, et al. Transient receptor potential cation channel, subfamily V, member 4 and airway sensory afferent activation: role of adenosine triphosphate. J Allergy Clin Immunol 2016; 138: 249-261.

6 Mukhopadhyay I, Kulkarni A, Aranake S, et al. Transient receptor potential ankyrin 1 receptor activation in vitro and in vivo by pro-tussive agents: GRC 17536 as a promising anti-tussive therapeutic. PLoS One 2014; 9: e97005.

7 Kollarik M, Ru F, Undem BJ. Acid-sensitive vagal sensory pathways and cough. Pulm Pharmacol Ther 2007; 20: 402-411.

8 Kwong K, Kollarik M, Nassenstein C, et al. P2X2 receptors differentiate placodal vs. neural crest C-fiber phenotypes innervating guinea pig lungs and esophagus. Am J Physiol Lung Cell Mol Physiol 2008; 295: L858-L865.

9 Wortley M, Dubuis E, BonviniJ S, et al. Making sense of sensory nerves: an in vitro characterisation of gene expression profiles of airway-innervating guinea-pig airway neurons using single-cell analysis [abstract]. Am J Respir Crit Care Med 2016; 193: A6002.

10 Morice AH, Higgins KS, Yeo WW. Adaptation of cough reflex with different types of stimulation. Eur Respir J 1992; 5: 841-847.

\section{Author response: The human cough reflex has separate, distinct pathways}

From the authors:

We thank J.A. Smith and co-workers for their interest in our paper [1]. Perhaps an even more ancient truth, that of William of Occam [2], should be applied to this discussion. 
We were the first to demonstrate that cough challenge testing reveals a fundamental mechanism for clinically important hypertussia, cough reflex hypersensitivity [3]. Whilst we agree the mechanism of this aberrant response remains to be fully elucidated, we believe our study does indeed reveal a fundamental dichotomy within the human cough reflex. That P2X3 and TRPV1 expression occurs within the same neurons appears true in resected vagal nerve fibres; however, we were careful not to claim the anatomical separation that is erroneously suggested by J.A. Smith and co-workers. As we point out "The more central pathways of the vagal afferents through the nodose and jugular ganglia to the solitary nucleus are extremely complex and varied, and exhibit marked plasticity and redundancy in disease. In this environment, the interpretation of cough challenge studies must be undertaken with care." To use Occam's razor, the simplest mechanism to explain our observations is that there are two biological/ pathophysiological cough pathways, one irritant and the other pathological, responsible for the hypertussia seen in chronic cough. Whether these pathways reside in the same or separate neurons remains to be elucidated.

With regard to isolated nerve studies, we are reminded of the old saying that to a physiologist an intact animal is one with all its organs in the same room. In cough, reliance on such models has led to several blind alleyways, as illustrated by the failure in the clinic of studies of TRPV1 [4,5] and TRPA1 [6] antagonists.

Our study was carefully designed to minimise any effect of repeat challenges with in patient randomisation of challenge order. As we point out, a post hoc analysis demonstrated no carry over effect. This objection is doubly surprising since the same findings regarding the effect (or lack of) of gefapixant on capsaicin and ATP challenge has been observed by SMITH et al. [7], though we are unable to fully comment on the challenge methodology from this abstract.

@ERSpublications

The human cough reflex has separate, distinct pathways http://bit.ly/2PZgybq

Cite this article as: Morice AH, Kitt MM, Ford AP, et al. Author response: The human cough reflex has separate, distinct pathways. Eur Respir J 2020; 55: 1902312 [https://doi.org/10.1183/13993003.02312-2019].

Alyn H. Morice ${ }^{1}$, Michael M. Kitt ${ }^{2}$, Anthony P. Ford ${ }^{2}$, Andrew M. Tershakovec ${ }^{2}$, Wen-Chi Wu ${ }^{2}$, Kayleigh Brindle ${ }^{1}$, Rachel Thompson ${ }^{1}$, Susannah Thackray-Nocera ${ }^{1}$ and Caroline Wright ${ }^{1}$

${ }^{1}$ Hull York Medical School, Cottingham, UK. ${ }^{2}$ Merck \& Co., Inc., Kenilworth, NJ, USA.

Correspondence: Alyn H. Morice, Respiratory Medicine, Hull York Medical School, University of Hull, Castle Hill Hospital, Castle Road, Cottingham, HU16 5JQ, UK. E-mail: a.h.morice@hull.ac.uk

Received: 3 Dec 2019 | Accepted after revision: 15 Dec 2019

Conflict of interest: A.H. Morice has received consulting fees from Afferent, Merck Sharp \& Dohme, Boehringer Ingelheim, Pfizer, and Proctor \& Gamble; lecture fees from Boehringer Ingelheim and AstraZeneca; and grant support from Proctor \& Gamble. M.M. Kitt is a former employee of Afferent Pharmaceuticals and Merck Sharp \& Dohme Corp., a subsidiary of Merck \& Co., Inc., Kenilworth, NJ, USA, and may own stock in the company. A.P. Ford is a former employee of Afferent Pharmaceuticals and Merck Sharp \& Dohme Corp., a subsidiary of Merck \& Co., Inc., Kenilworth, NJ, USA, and may own stock in the company. A.M. Tershakovec is a former employee of Merck Sharp \& Dohme Corp., a subsidiary of Merck \& Co., Inc., Kenilworth, NJ, USA, and may own stock in the company. W-C. Wu was an employee of Merck Sharp \& Dohme, Corp., during the conduct of the study. K. Brindle has nothing to disclose. R. Thompson has nothing to disclose. S. Thackray-Nocera has nothing to disclose. C. Wright has nothing to disclose.

\section{References}

1 Morice AH, Kitt MM, Ford AP, et al. The effect of gefapixant, a P2X3 antagonist, on cough reflex sensitivity: a randomised placebo-controlled study. Eur Respir J 2019; 54: 1900439.

2 Schaffer J. What not to multiply without necessity. Australas J Philos 2015; 93: 644-664.

3 Morice AH, Lowry R, Brown MJ, et al. Angiotensin-converting enzyme and the cough reflex. Lancet 1987; 2 : 1116-1118.

4 Khalid S, Murdoch R, Newlands A, et al. Transient receptor potential vanilloid 1 (TRPV1) antagonism in patients with refractory chronic cough: a double-blind randomized controlled trial. J Allergy Clin Immunol 2014; 134: $56-62$.

5 Belvisi MG, Birrell MA, Wortley MA, et al. XEN-D0501, a novel transient receptor potential vanilloid 1 antagonist, does not reduce cough in patients with refractory cough. Am J Respir Crit Care Med 2017; 196: 1255-1263.

6 Morice AH. TRPA1 receptors in chronic cough. Pulm Pharmacol Ther 2017; 47: Suppl. C, 42-44.

7 Smith J, Kitt M, Butera P, et al. S27 The effect of P2X3 antagonism (AF-219) on experimentally evoked cough in healthy volunteers and chronic cough patients. Thorax 2016; 71: Suppl. 3, A17. 